\title{
Several notes on technical modernization of a historical building
}

\author{
J. Bakowski \\ Faculty of Architecture, Gdansk University of Technology, Poland
}

\begin{abstract}
This paper describes methods and means used during the renovation process of several elements of a building - the assembly hall, inner courtyards and attics of the main building at Gdansk University of Technology, both in design and construction domains. A tissue of a historic building required special approach to these tasks, with special emphasis on good recognition of problems, careful planning and consistent implementing of proper solutions.

Keywords: historic building refurbishment and modernization, technical equipment of historical building.
\end{abstract}

\section{Introduction}

The finial of the main building of the Gdansk University of Technology with the reconstructed clock-tower ends next phase of works related to the renovation and modernization of the building. Problems and achievements, reviewed in the course of more than 10-year work can be a contribution to describe the design methods and can help finding general principles or rules that were used during this work. While at first glance one would reduce the renovation to equipment and refresh of several lecture halls or workshops, inner courtyards, adaptation of the attics or reconstruction of the clock-tower - these are the most characteristic elements of the work done - the essence of the design issues is hidden from the eyes of the average user. Adapting the building to today's user requirements, providing adequate level of stay comfort, meeting technical standards, security, these are the elements that may seem obvious and natural. Putting them into the structure of the historic building is not always easy to carry out.

The scope and complexity of works carried out during the modernization could be good bases for general conclusions for other similar works. Of course, 
these are not universal recommendations - variety of construction techniques, spatial solutions, user requirements cause the renovation and refurbishment of such objects will always stay an issue to be discussed. Nevertheless, one may be tempted to find some common elements that can be used in similar assumptions.

\section{Subject of research}

Any modernization of a building, especially a historic one, requires the solution of problems characteristic and unique for this type of projects. Construction of building from scratch allows us to resolve design issues freely, designer decides how his spatial concept will meet the specific requirements - if a parameter does not respond, the structure of the building can be easily changed or transformed. In case of newly designed buildings there are a multitude of possible solutions that make it possible to shape their forms and also their inner infrastructure - a construction, installations, functional connections and more. Of course, the valid question is how newly designed building are subject of possible changes in the future? Assuming a lifespan of the facility and its operation consistent to the designed primary function, in the long run one should always take into account the need or urge to introduce changes, even minor ones. Though an interesting problem, the evaluation of the functional and architectural solutions in this respect is beyond the scope of this article.

In case of refurbishment of existing buildings there is no comfort to choose the structure of the building, and all chosen actions must be placed in a readymade setting, where any changes and interventions are limited. By "structure" I mean not only the design, but the whole setting of technical solutions and equipment needed for proper functioning of the object. So it can be any internal installation, technical equipment or even elements of the interior design.

All the design problems, i.e. all the issues of functional layout (proper functional relationships and connections, the quality of the space), the safety of the structure (modernization or replacement of static systems), fire safety (zoning, setting and length of the escape routes, alarm systems), equipment installation (heating, ventilation and air conditioning), maintenance and conservation issues (repair and reconstruction of architectural and structural elements) require not only individual solutions. Also there is a need to find a suitable place for them in the existing structure of the object. Obviously, for buildings of similar historical, spatial or structural systems one can find common or similar solutions. Likewise, for the adjustment of different objects to perform similar functions one can also find common solutions and components. These assumptions allow drawing more general conclusions, despite significant differences between individual cases.

\section{Design and its implementation}

The case of the edifice of Gdansk University of Technology concerns the modernization and refurbishment which is still in progress. In short, the chosen research method involves practical checking of design assumptions. During the 
design works there were prepared several alternative solutions, each one was a subject to verification, especially in terms of feasibility. Several factors were taken into account: technical (possibility to implement solutions in a historic structure, susceptibility to changes during operation of a building), spatial (correctness of architectural solutions), economic (cost of installation, possibility of staging the investment and construction during normal functioning of the building). Modelling of several alternative solutions was preceded by numerous studies and analyzes concerning the building, as well as the available technical means.

Problems that the design team encountered during the last ten years of practice can be divided into a number of categories. It is worth noting that the team consisted of almost 40 specialists of various industries: architects, structural engineers, civil and installation engineers, conservators, interior designers, surveyors and others. The cooperation and unanimous team work was a key to the successful venture and the presented case study describes how such a cooperation looks from the point of view of an architect.

\subsection{Maintenance and repair of the building structure}

Construction and related issues, in terms of duration of the object, obviously depends on the proper evaluation of the existing structure. Most of the damage done to the main building of the University has been repaired and the structural system of the building did not raise any major objections. There was no need for any deep interventions, beyond a few repairs and strengthening of some minor elements, as wooden attic structural elements or gables. On the other hand, there was a strong need to solve several problems that had been caused by the postwar reconstruction of the building. It was conducted after 1945 and was fast what does not mean that it was proper and respecting the state of art. The original principles which in 1902 guided Albert Carsten, the master designer of Königliche Technische Hochschule zu Danzig (fig. 1), derived from the $19^{\text {th }}$ century industrial methods of construction (besides the Dutch neo-renaissance façade).

The scope of the war damage was enormous: the floors, attics and clocktower collapsed due to the bombing and fire (fig. 2). The reconstruction was carried ignoring the knowledge of the building, using the ways and means completely incompatible to its character. Of course, the then state of knowledge and the need for rapid restoration forced such an action. Now we know how important it is to analyze existing building structure, its design solutions, in terms of the selection of the proper static and material solutions [3].

The recent refurbishment, apart from the above mentioned corrective actions, introduced new structures fit in the existing object. Selected specific solutions included not only static requirements, but also the degree of interference in the structure of the building. Where it was possible, all solutions had used elements of the existing static system of the building. 


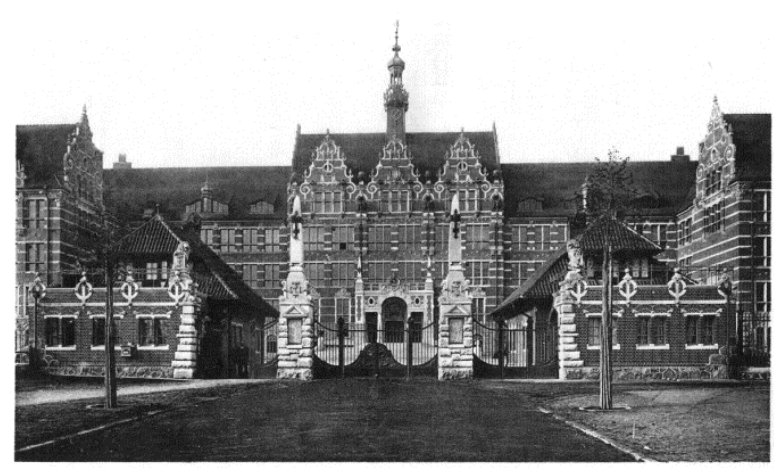

Hauptzugang von der Goßler-Allee.

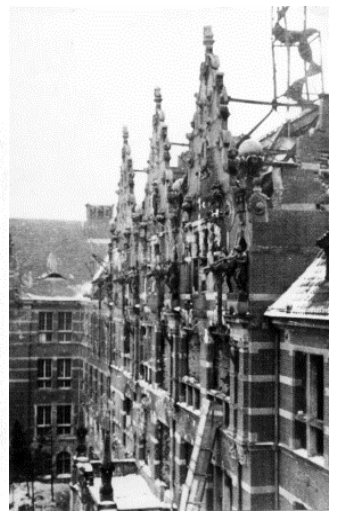

Figure 1: Facade of the main building of Königliche Technische Hochschule zu Danzig, ca. 1902 [4].

Figure 2: WWII damage, photo courtesy: archives of the University.
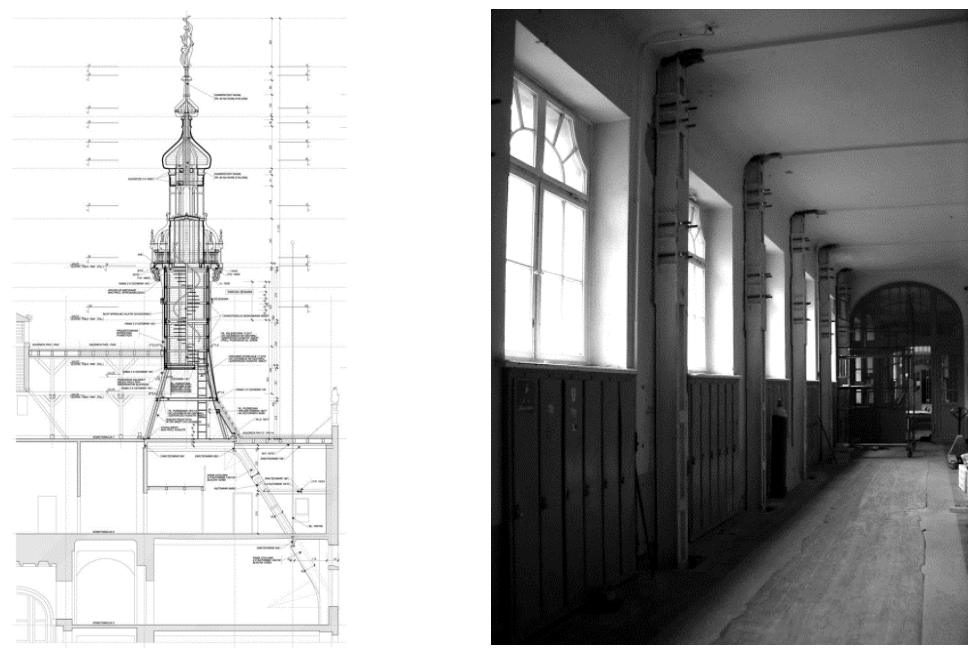

Figure 3: A section through the Figure 4: Pillars supporting glazing clock-tower. trusses.

The first way relates to, for example, the construction of stylized chimneys (air intake and outlet) and the foundation of reconstructed clock-tower - their base geometry had been designed to fully integrate with the original steel frame system (fig. 3). The second case is illustrated by the support of glazing trusses at the inner courtyards, permanently connected with peripheral masonry walls and floors by installing load-bearing system pillars (figs 4 and 5). The examples allow for balanced and direct transfer of loads of new elements to existing structural elements of the building. 


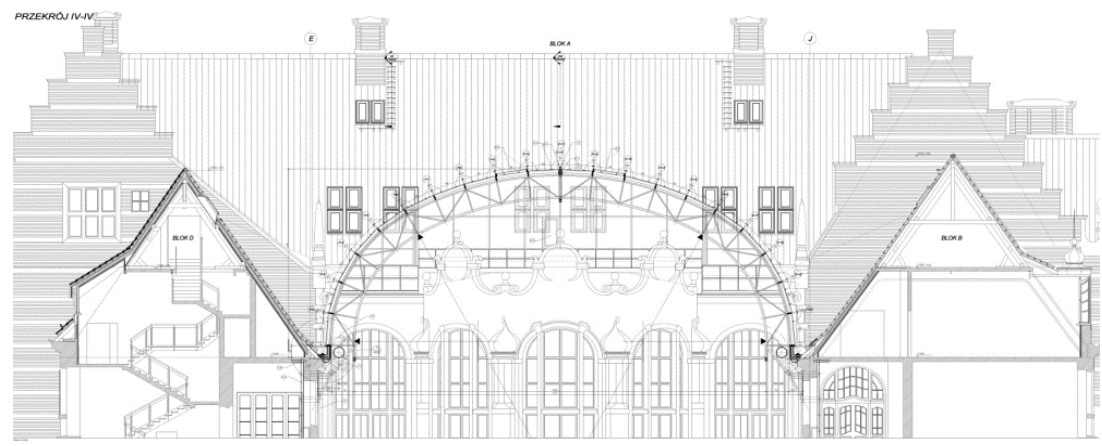

Figure 5: A section through the courtyard, showing construction of trusses.

The new basement at the courtyards is a special and separate task, where the floor level goes below the foundation level of courtyard walls. The proposed solution uses a cement injection method and still waits to be realized.

\subsection{Restoration and maintenance of historic substance}

Comparing the condition of the main building of the University in 2002 with its original condition, it turned out that apart from the elevations and the basic functional layout there had been changes in fundamental principles regarding mostly its interior architecture. The original design, with rich stucco decorations had been completely lost. In the course of post-war reconstruction many elements had been changed, including the "eclectic" design (fig. 6), replaced by the "modern" or even "soc-realistic" one. There are very few photographic documentation showing the details of these solutions, in addition (though it may seem a trivial premise) the "modern" designed became established by the University community as the ever-lasting one. Basing on such conditions, it had been decided that in case of interior design the refurbishment principles would

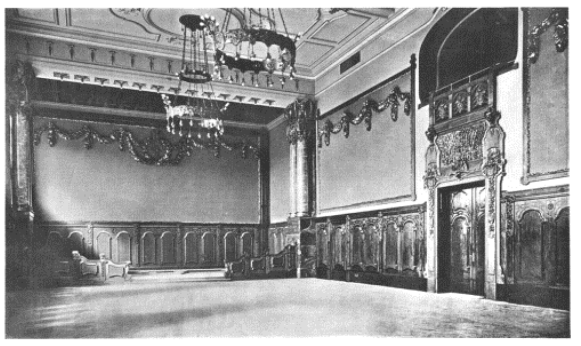

Figure 6: The main assembly hall, ca. Figure 7: 1902, photo courtesy: archives of the University.

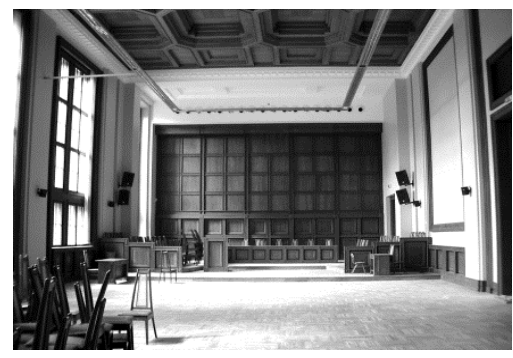

The main assembly hall, 2006 (during the refurbishment). 
rely on maintaining the post-war modernization (fig. 7) and the elevations would restore the original design concept of the Carsten project.

A much bigger problem arose from glazing and adaptation of both courtyards; they completely lost their character and had been gradually filled with inferior technical features and workshops. For many years the building occupants weren't even aware of their existence (figs 8 and 9). The decision on the courtyards revitalization was a key element in the modernization of the building and forced the introduction of other elements.

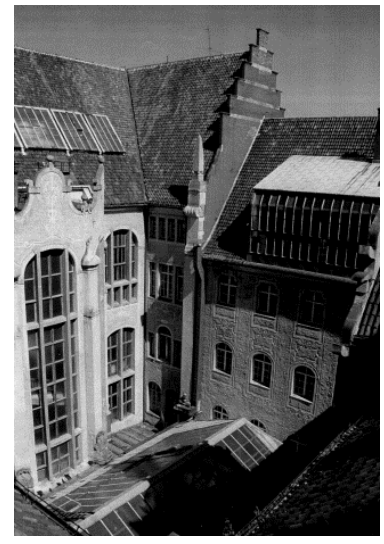

Figure 8: $\quad$ The southern Figure 9: courtyard, ca. 1995.

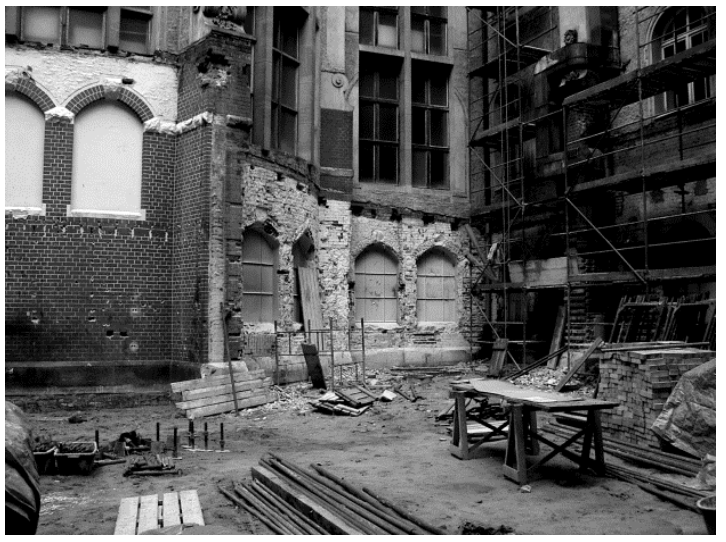

Figure 9: The southern courtyard, during the refurbishment, 2004.

From the conservator's point of view the carried works had not constituted great challenge, as the used techniques belonged to the canon of restoration works. Let's stay for a while with the preparation, arrangement and implementation of design documentation. The basis for the preparation of the project was detailed measurements and inventory drawings, on which the further analysis had based. In a simplified way, these analyses might be called "reverse engineering", as they allowed to "discovering" long forgotten spatial and functional relationships, structural solutions and infrastructure relations, including natural ventilation system. Unfortunately, they also showed that the reuse of these primary elements of the building was not possible - many years of negligence and almost constant rebuilding completely and irreversibly damaged these elements.

The chosen method of preparation of inventory documentation may seem to be archaic now: it relied on manual measurement, preparation of sketches and drawings, and finally on the preparation of the "normal" drawing with a CAD programme. In contrast, comparing to data collecting or measuring with scanning devices it had several advantages: it allowed the rapid preparation of simplified documentation, not burdened with excess of details and taking into account the most important features of the object. Thus prepared documentation 
contained information filtered for suitability to particular purpose. Advantages and disadvantages of manual and automated studies had been already presented in the literature [2]; it is worth to mention another factor favouring a quick manual sketch: the hand-made drawing was not a goal itself, it served as a starting material for further studies of project documentation. The most serious drawback of the method was the human factor: the possibility of occurrence of measurement errors, difficult to correct with inaccuracies multiplied by the misinterpretation of the drawing. However, regardless of these disadvantages, the geodetic laser measurement of courtyards' coordinate geometry and crucial points for support trusses had showed that design errors were small (of the order of a few millimetres for a span of $2503 \mathrm{~cm}$ ) and completely reversed by the applied tolerances of the supporting consoles.

The next issue worth discussing was the reconstruction of the architectural elements of the building. Problems associated with the reconstruction can be divided into two categories: recreating formal and spatial solutions (shape and size of an element) and technical ones (structure, construction and finishing materials). One of the tools for the former method was restitution of perspective. Basing on descriptive geometry methods (and it did not matter whether the drawing construction would be created manually or using a CAD system) one could analyse a photographic documentation to restore dimensions of an element as well as decorative ornaments (if the quality of photographic documentation was sufficiently good). The method helped to reconstruct the clock-tower. The quality of photographs did not allowed to strictly project all the details, so the sculptor had been entrusted the task of preparing the new figure of science allegory (fig. 10). All the tower details had been modelled with the 1/10 scale before the final acceptance. The more, analyses of similar technology solutions, from the same period (the clock-tower of the main railway station in Gdansk was built at about the same time, using exactly the same technology) helped to prepare detailed drawings for the reconstruction (fig. 11).

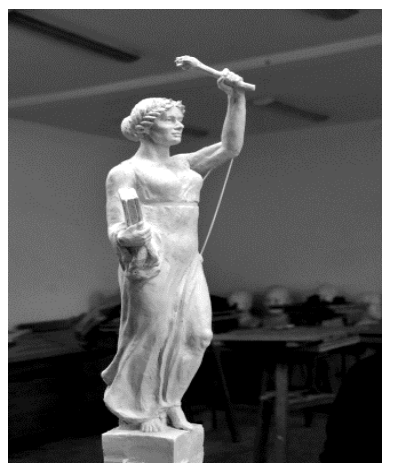

Figure 10: A model of the science allegory.

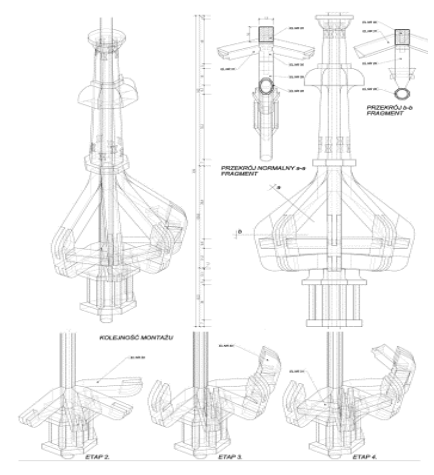

Figure 11: Details for clock-tower construction. 


\subsection{Fire safety}

The range of possible security codes for any building includes a full range of solutions from simple, passive methods (fire divisions, zoning, provision of evacuation routes of suitable length) to complex ones (fire alarm, extinguishing systems, smoke extraction). It would seem that in the case of the historic building the passive solutions are simpler and easier to implement. Such an approach does not guarantee the correct and working solutions. It is rare instance that we are able to build another evacuation staircase or even adapt existing one for fire safety purposes (for example, by the addition of vestibule or enclosure with inflammable structures). The introduction of technical solutions requires expand the infrastructure of the building: a constant supply of water, distribution of sprinkler system (which is rarely in line with the requirements of historic preservation). The best solution is to find a compromise between the fire protection requirements and the architectural concept of the building or historic preservation requirements. In both cases, the Polish law is quite restrictive, but allows for certain exceptions to its own rules.

The problem has been widely discussed by Aiello et al. [1] and it is worth noting in this work statement: there is no universal method to adapt to the requirements of the historic building fire protection.

In the case of the main building of the University there was used the whole set of fire protection systems and elements. An additional fire-safety staircase was placed as well as lift shaft, built with parameters appropriate to carry out the emergency operations. The existing staircases will be separated with vestibules, with supplementary fire protection system consisting of the fire-alarm and sprinklers layout (the latter element still stirs up controversies, as it contravenes conservation guidelines for the building). To supply the system with sufficient amounts of fire water there will be a tank with a capacity of $185 \mathrm{~m} 3$ in the basement, just under one of the courtyard (fig. 12).

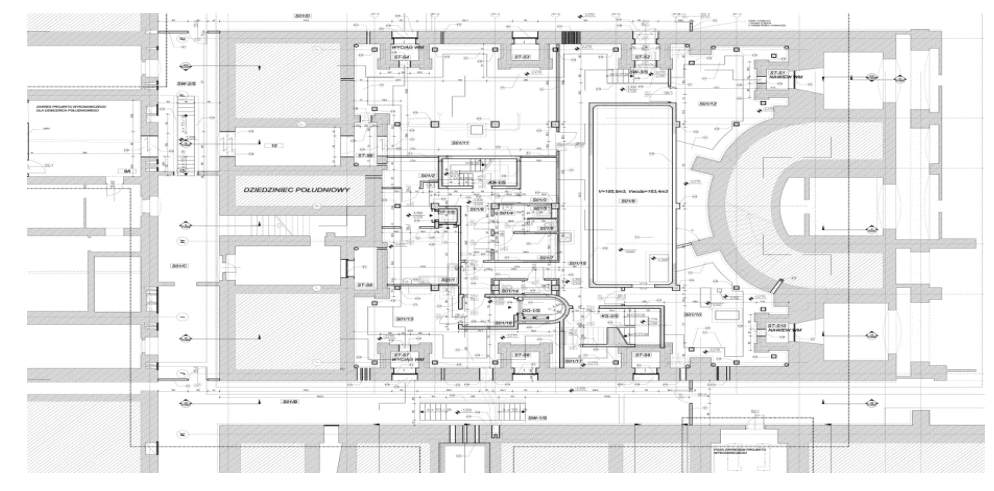

Figure 12: The basement plan, showing elements of the building infrastructure (HVAC machine rooms and fire-safety water tank). 


\subsection{User's comfort}

Under this fairly general theme there is an entire set of activities strongly interfering with the structure of the building and causing the most serious design problems. While in the early years of the University its main building could hold up to 500 professors and students, now the number increased several times. Also, there were other major changes: user preferences, requirements and regulations for user comfort in a building. The need for ventilation in a multi-storey, historic building is a difficult task itself.

The first premise leading to valid solutions took its origins from fire safety arrangements. As the building was divided into parts in a natural way (with massive firewalls), it was decided that those divisions would also apply in the case of internal infrastructure. In addition, with the existing and rigid spatial and functional layout of the building it was not possible to set any straight and regular installation shafts. The similar restrictions were valid for the horizontal distribution. The building natural fire blocks thus were further divided vertically, so the separate infrastructure layouts could be assigned to the three lower storeys (with machine rooms at the basement) as well as the three upper storeys (with machine rooms at the attics). These assumptions were translated into the adoption of a distributed system of mechanical ventilation (or even HVAC at the main assembly hall or the Senate hall) and each separate part of the building was supported by at least two pairs of ventilation handling units with air inlet and outlet (fig. 13).

At the central part of the building there are several special rooms located, with the largest capacity and labour demands on the ventilation system (Senate halls, main auditorium and assembly hall, the library, art studies and workshops),

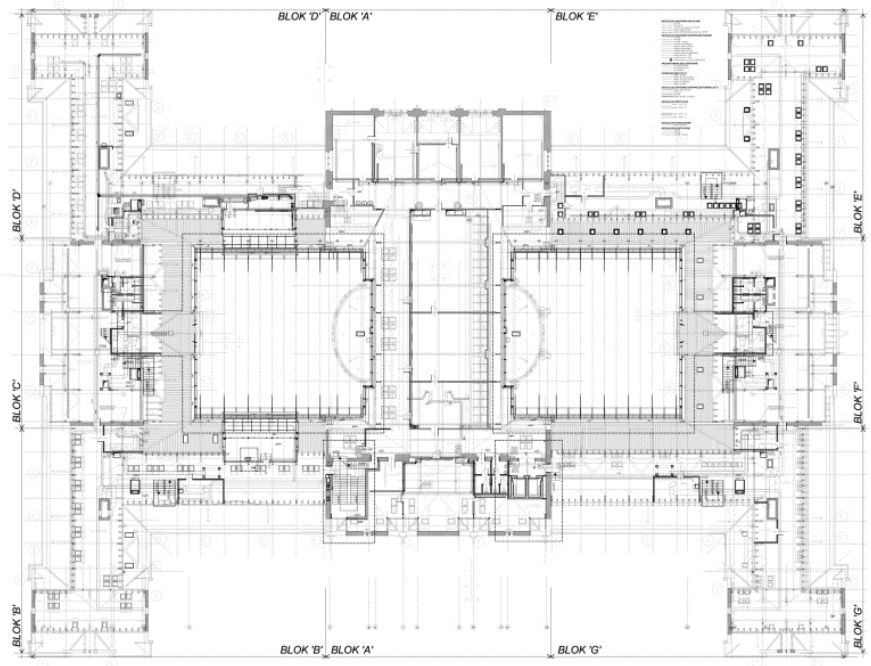

Figure 13: Attics layout, showing the infrastructure and division to fire-safety blocks. 
and therefore the special and custom solutions had to be adopted in this part of the building. It was assumed that the layout, with its automation and machine rooms, would become more fragmented (in order to improve the operating performance and to avoid potential functional and technical draw-backs). Restrictions imposed by conservation regulations forced that the applied external components of the ventilation system were designed as stylized elements (new chimneys) or others elements received this function (the clock-tower as the air outlet) (fig. 14).

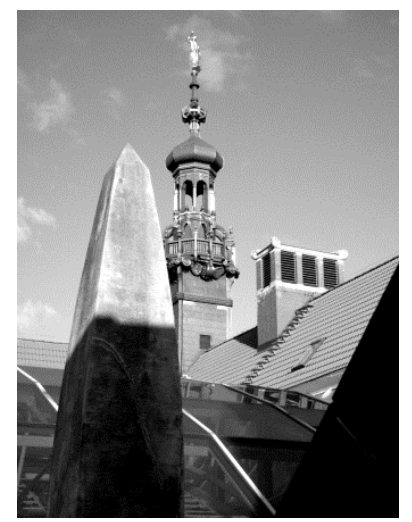

Figure 14: Architectural elements of the building infrastructure.

\subsection{The organization of the investment}

Apart from economic issues, from a designer's point of view, the most important question concerning the preparation and the implementation of the project was a proper distribution into several phases or stages. A one-time execution of all solutions was not possible for several reasons: first of all because of the funds available and, maybe the more important, the investment planning. While the original idea of modernization and refurbishment of the building derived from the willingness to adapt the attics for classrooms or workshops and to make the courtyards the vivid element of the university campus, all the remaining tasks were the consequence.

The above-mentioned elements (construction safety, fire safety, comfort) for the average user were natural elements of each building. Their introduction into the structure of the building should precede any other adaptation. When properly recognized and finished these elastic and sensitive to changes solutions could be set up to incorporate functions in virtually any field. The only restriction posed to the architectural and interior design solutions, resulted from the designed structural and installation system, just as is the case of newly designed buildings. Another realization problems, such as the selection of the specific technologies or assembly techniques, depended on the chosen fabrication methods and organization of the building-site. Such implementations didn't vary in any 


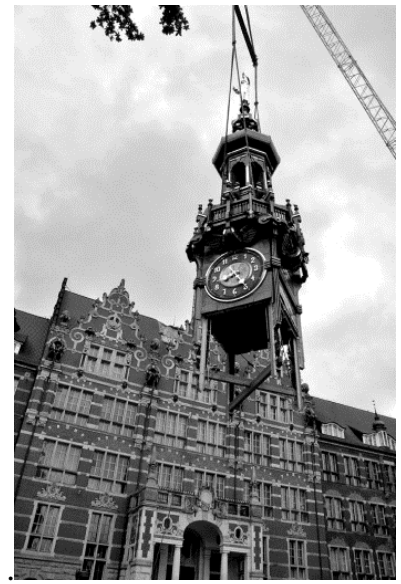

Figure 15: Assembly of the trusses for glazing.

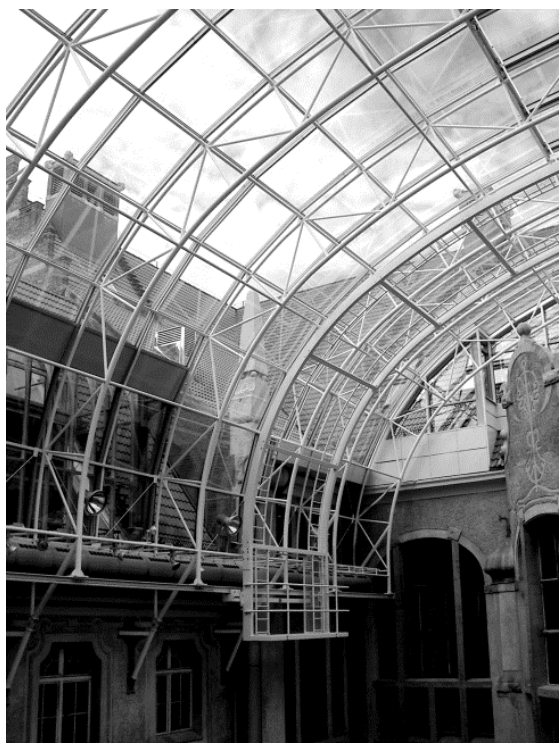

Figure 17: $\quad$ Glazing of the courtyard.

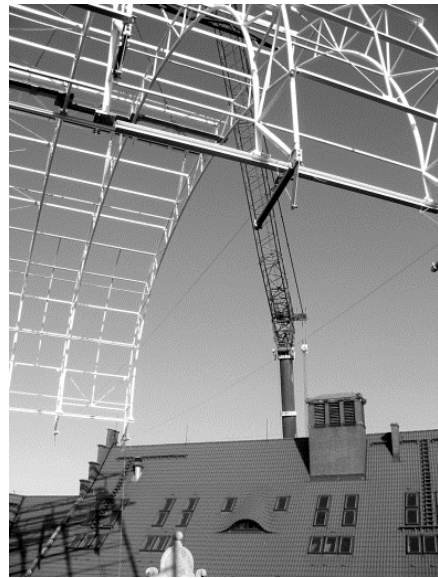

Figure 16: Mounting the clocktower.

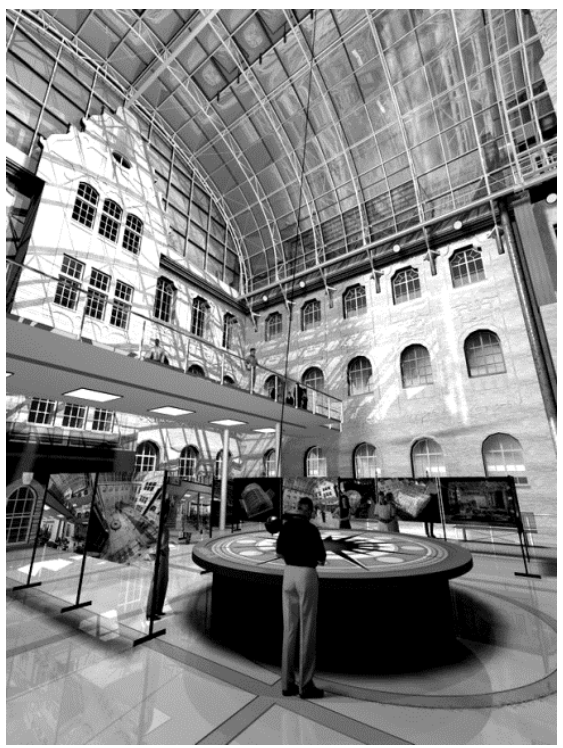

A vision of the further modernization.

specific way from the construction of new buildings. Of course, there were some specific cases solved with non-standard technologies and concerning some aspects of the off-side manufacturing (fabrication of steel trusses for the courtyards glazing or construction and decorations of the clock-tower). The basic structure of these elements were produced at the contractors' workshops, then assembled, lifted and mounted at the place (figs 15 and 16). 


\section{Conclusions}

The presented paper concentrates on the collaboration of all design participants, and their effort to gain the basic goal - the appropriate, diligent and thorough modernization and refurbishment. As there are several possible solutions, and there is no single "winning” strategy for a building refurbishment. All the taken actions have to be adaptive for the building purposes, nowadays as well as in the future (figs 17 and 18).

\section{References}

[1] Aiello M., Astrua F., Nelva R., Vancetti R. and Rella M., Fire safety measures in historic buildings for university use, Fire Technology, 38, pp. 345-362, 2002.

[2] Callieri M., Cignoni P., Scopigno R., Gori G., and Risaliti M., Beyond manual drafting: a restoration-oriented system, Journal of Cultural Heritage, 7, pp. 214-226, 2006.

[3] Croci G., General methodology for the structural restoration of historic buildings: the cases of the Tower of Pisa and the Basilica of Anisi, Journal of Cultural Heritage, 1, pp. 7-18, 2000.

[4] Technische Hochschule in Danzig - Festschrift zu Eröffnung, 6 October 1904. 